\title{
NUEVA ESPECIE DE NESOCYRTOSOMA MARCUZZI, 1976 \\ (COLEOPTERA: TENEBRIONIDAE: COELOMETOPINI) DE LA REPÚBLICA DOMINICANA
}

\author{
Orlando H. Garrido ${ }^{1}$ y Carlos Varela ${ }^{2}$ \\ ${ }^{1}$ Calle 60 \# 1706 e/e 17 y 19, Playa, C. P.11300, Ciudad de La Habana, Cuba. \\ ${ }^{2}$ Acuario Nacional de Cuba, Calle 1ra \#6002 e/e 60 y 62, C. P. 11300, Playa, Ciudad de La Habana, Cuba.
}

RESUMEN

Una especie nueva perteneciente a la tribu Coelometopini de la familia Tenebrionidae, encontrada en la República Dominicana, es descrita e ilustrada.

Palabras clave: Coleoptera, Tenebrionidae, Coelometopini, nueva especie, República Dominicana.

\section{ABSTRACT}

A new species belonging to the tribe Coelometopini of the family Tenebrionidae, from the Dominican Republic, is described and illustrated.

Key words: Coleoptera, Tenebrionidae, Coelometopini, new species, Dominican Republic.

\section{INTRODUCCIÓN}

Durante los últimos tres años se han venido realizando expediciones con énfasis en la colecta de invertebrados en la República Dominicana. De esas expediciones se ha acumulado un abundante e interesante material de insectos, miriápodos, arañas y alacranes, algunos de ellos constituyen nuevos registros de géneros y especies, no sólo para la República Dominicana, sino también para la ciencia.

El género Nesocyrtosoma Marcuzzi, 1976, es netamente antillano. Especies del mismo se encuentran en las islas de Cuba y La Hispaniola, en las Antillas Mayores y en Martinica, Granada y Trinidad, en las Antillas Menores, a diferencia del cercano género Cyrtosoma cuyas especies son continentales. Del género Nesocyrtosoma se han registrado para República Dominicana siete especies (Pérez-Gelabert, 2008). De éstas, solo dos son recientes mientras que las restantes son fósiles que han sido halladas en ámbar (Doyen y Poinar, 1994).

En esta contribución nos concretamos a describir una nueva especie de coleóptero perteneciente al género Nesocyrtosoma. El hallazgo de esta especie tan diferente de las conocidas para el género no debe sorprender, si se tiene en cuenta lo poco que ha sido estudiada la entomofauna de la isla, y sobre todo la familia Tenebrionidae (Pérez-Gelabert, 2008).

\section{MATERIALES Y MÉTODOS}

Se llevaron a cabo colectas en el campo en los meses de febrero del 2002 y noviembre del 2003 en Las Mercedes, provincia de Pedernales, Republica Dominicana. La colecta se realizó manualmente y para ello se revisaron troncos caídos, hojarasca, debajo de piedras y dentro de bromelias. Los individuos fueron pasados a un frasco con alcohol, luego montados en un alfiler entomológico y bajo un microscopio estereoscopico se observaron los caracteres de los mismos. Los dibujos del pronoto y el genital del macho se realizaron con ayuda de la cámara clara. El material estudiado se encuentra depositado en el Museo Nacional de Historia Natural de Cuba (holotipo) y en la colección personal del primer autor (paratipos). 


\section{RESULTADOS}

\section{SISTEMÁTICA}

Orden Coleoptera Linnaeus, 1758

Familia Tenebrionidae Latreille, 1802

Nesocyrtosoma bromelicolus sp. nov.

(Figs. 1-3)

Diagnosis. Especie de Nesocyrtosoma de tamaño grande $(11 \mathrm{~mm})$. Pronoto rectangular con la base sinuosa y bordes laterales crenulados.

Diagnosis. A species of Nesocyrtosoma of big size $(11 \mathrm{~mm})$. Pronotum rectangular with sinuose base and crenulated lateral edge.

Descripción. Cabeza. Grande, semiredondeada, de color negro, con el clypeus bien delimitado y convexo; con puntuaciones homogéneas y más pequeñas que las del vértice que son del doble de tamaño y más profundas. Genas ligeramente punteadas, algo elevadas y lustrosas, con un lustre que contrasta con el negro de la cabeza. Ojos grandes, arriñonados y brillantes, que se continúan por su superficie inferior. Antenas cortas que no llegan a la base del pronoto. Superficie ventral, de color castaño oscuro, con las piezas bucales, especialmente los palpos maxilares, del mismo color que las antenas; garganta semi-lustrosa y bordeada por numerosas punciones, algunas amalgamadas (Fig. 1).

Pronoto rectangular, con la base más pequeña que la de los élitros, de color negruzco con ligero viso verdoso y con finas puntuaciones homogéneamente repartidas en toda su superficie. Poco abovedado y bien separado de los élitros, con los costados laterales semi-arqueados y conspicuamente crenulados, con dos o tres orlas en su parte media y con los ápices muy desarrollados, puntiagudos y salientes, extremos de la base en ángulo recto (Fig. 2). Marcada impresión longitudinal en la parte inferior a la altura del escutelo. Prosternum en forma de lengüeta corta, más ancha en su extremo final, separada de las coxas por dos impresiones punzadas, una a cada lado que contrastan en coloración con las coxas, que son divididas y no globosas.

Escutelo grande, triangular y muy ligeramente punteado.

Élitros muy largos, unas cuatro veces el largo del pronoto, más estrechos en el tercio apical y más anchos en su mitad, disminuyendo paulatinamente hasta el ápice; no fundidos en su sutura media donde se distinguen parte de las alas. De un viso metálico violáceo con ocho hileras simétricas de punciones redondas, poco profundas y separadas entre sí, espacio entre las hileras liso. Otras dos hileras cortas en el tercio apical, una a cada lado del escutelo con punciones similares pero ligeramente más profundas.

Epipleura con los hombros salientes en ángulo recto. Mesosternum corto, de un color castaño más claro que el de los miembros y más elevado por encima de las coxas. Metasternum grande, sub-rectangular, lustroso con puntuaciones en toda su superficie.

Esternitos prácticamente lisos, con la parte superior del segundo y tercero ligeramente estriados; resto de la superficie lisa y semilustrosa. Último esternito con muy finas puntuaciones.

Miembros largos, de color castaño oscuro, más oscuros que las coxas y piezas bucales, con los fémures rectos, el doble de ancho que las tibias, punzados y más engrosados en la coyuntura superior. Tibias prácticamente del mismo largo que los fémures, ligeramente arqueadas y del doble de largo que los tarsos, que son pilosos en su superficie inferior con las garras muy desarrolladas. En el primer y segundo par de patas, todos los artejos son similares en tamaño, en el tercer par, el primero es del tamaño del segundo y tercero juntos. 


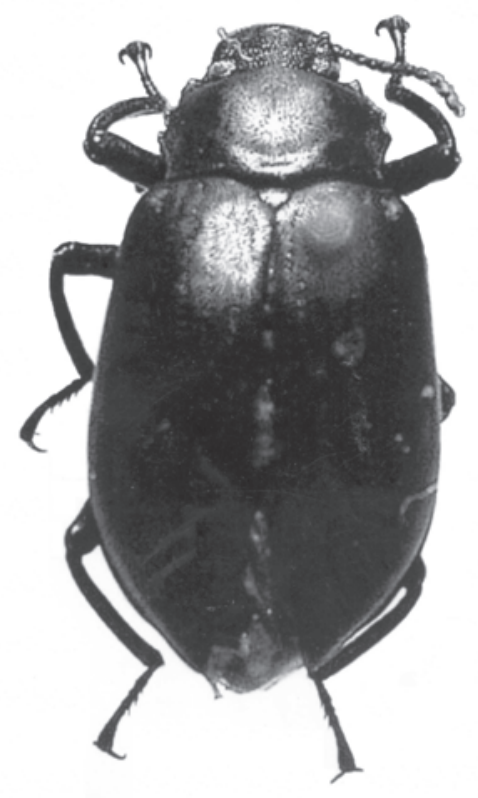

Eᄐ|

Figura 1. Nesocyrtosoma bromelicolus sp. nov.

Vista dorsal del holótipo.

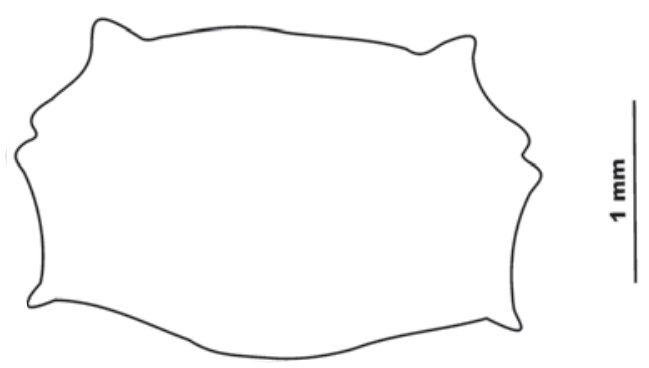

Figura 2. Nesocyrtosoma bromelicolus, sp. nov. Vista dorsal del pronoto.
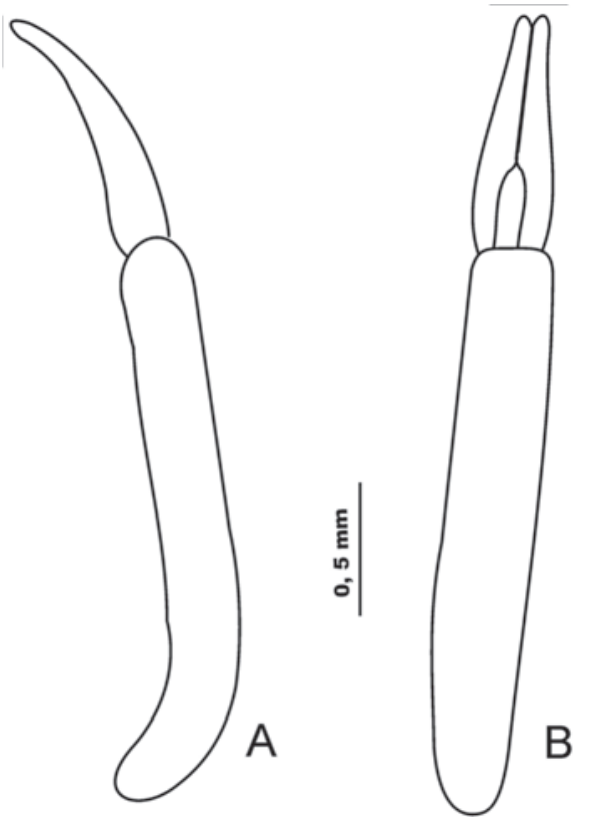

Figura 3. Nesocyrtosoma bromelicolus sp. nov.

A. Vista lateral del genital del macho.

B. Vista dorsal del genital del macho. 
Genital del macho como se observa en la Figura 3.

Variación. Los insectos colectados en las bromelias son similares al holotipo en tamaño, coloración y patrón de relieve. Los dos obtenidos en la misma localidad pero bajo piedras, se diferencian en coloración al ser totalmente negros sin viso violáceo alguno y por ser ligeramente más pequeños (9-10 $\mathrm{mm})$ contra $(9.5-11 \mathrm{~mm})$ los de las bromelias. De manera general pueden tener a cada lado del pronoto de 2 a 3 orlas cada ejemplar, aunque algunos tienen 2 de un lado y 3 del otro.

Tipos. Holotipo: O. H. G. 2977 (11 mm). Colectado en Las Mercedes, provincia de Pedernales, República Dominicana, el 18. xi. 2003, por Julio Antonio Genaro, Esteban Gutiérrez y Héctor Andújar en bromelias. Depositado en el Museo Nacional de Historia Natural de Cuba. Paratipos: O. H. G. 2978, 2979, 2981, 2982, colectados en bromelias y H. G. 3009 y 3010, colectados bajo piedras. Mismos datos que el holotipo, depositado en la colección del autor principal.

Etimología. Bromelicolus se deriva de la planta en donde se hallaron los ejemplares que es conocida como bromelia o curujey.

Comentario. La especie descrita en el presente trabajo se diferencia de las anteriormente descritas especies del género Nesocyrtosoma por presentar, unido a su tamaño grande, los márgenes laterales del pronoto crenulados.

\section{AGRADECIMIENTOS}

En primer lugar al ingeniero conservacionista Víctor L. González por el auspicio de estas expediciones a la República Dominicana. A Yvonne Arias y miembros conservacionistas del Grupo Jaragua, que hicieron posible el éxito de estas expediciones. A los colegas cubanos que participaron en las colectas, los especialistas, Esteban Gutiérrez, Giraldo Alayón, Julio Antonio Genaro y Antonio Pérez-Asso, así como la ayuda brindada por el estudiante dominicano Héctor Andújar y la fotógrafo norteamericana Laura Watson.

\section{LITERATURA CITADA}

Doyen, J. T. y G. U. Poinar, Jr. 1994. Tenebrionidae from Dominican amber (Coleoptera). Entomol. Scand. $25(1): 27-51$.

Perez-Gelabert, D. E. 2008. Arthropods of Hispaniola (Dominican Republic and Haiti). A check list and bibliography. Zootaxa 1831: 1-530. 